\title{
Quiste hepático simple gigante como causa de disnea en paciente de 93 años
}

\author{
O. MACHO PÉREZ, J. GÓMEZ PAVÓN, A. NÚÑEZ GONZÁLEZ, L. NARVAIZA \\ GRAU, L. ALBÉNIZ AGUIRIANO ${ }^{1}$
}

Servicios de Geriatría y 'Radiología. Hospital Central de la Cruz Roja. Madrid

GIANT SIMPLE HEPATIC CYSTS AS DYSNEA SYMPTOM IN A 93 YEARS OLD PATIENT

\section{RESUMEN}

El quiste hepático gigante simple, se suele presentar de forma asintomática en torno al 3\% de la población adulta. Se presenta el caso de una mujer de 93 años en que se diagnostica tras la aparición de disnea súbita, realizándose tratamiento evacuador y posterior introducción con fenol. Se realiza a su vez una revisión de las lesiones quísticas hepáticas, asî como del tratamiento del quiste hepático simple.

PALABRAS CLAVE: Quiste hepático gigante. Anciano. Tratamiento.

\section{ABSTRACT}

Giant simple hepatic cysts is generally asymptomatic in the $3 \%$ of cases of adult patients. We present a woman case of 93 years old who was diagnoses of giant simple hepatic cyst presented as dysnea. The management of this patient was with percutaneous aspiration and fenol alcohol. It made a review of cystic lesions of the liver and of simple hepatic cysts management.

KEY WORDS: Giant simple hepatic cysts. Elderly. Treatment.

Macho Pérez O, Gómez Pavón J, Núñez González A, Narvaiza Grau L, Albéniz Aguiriano L. Quiste hepático simple gigante como causa de disnea en paciente de 93 años. An Med Interna (Madrid) 2007; 24: 135-137.

\section{INTRODUCCIÓN}

Los quistes hepáticos simples son formaciones de contenido líquido-seroso, rodeadas de un parénquima hepático normal sin comunicación con la vía biliar intrahepática, estando presente en torno al 2-7\% de la población adulta $(1,2)$.

La mayoría son asintomáticos y suelen ser un hallazgo casual. Los síntomas se presentan ante su gran tamaño o bien por la presencia de complicaciones como la hemorragia, la rotura o la infección intraquística, así como por la compresión de estructuras adyacentes. Se pueden tratar de forma expectante, percutáneamente (aspiración con o sin inyección intraquística de alcohol u otras sustancias esclerosantes) o quirúrgicamente.

Se presenta el caso de una mujer de 93 años en el que se le diagnostica tras la aparición de disnea súbita, realizándose tratamiento evacuador y posterior introducción de alcohol al $99 \%$.

\section{CASO APORTADO}

Mujer de 93 años que ingresa en la unidad geriátrica de agudos (UGA) tras acudir a urgencias por aumento súbito de su disnea habitual y aparición de edemas de los miembros inferiores. Refería una cardiopatía hipertensiva con disnea III/IV NYHA con dos ingresos previos; neo de mama izquierda diagnosticada hace 4 años en tratamiento con hormonoterapia y faquectomía izquierda. Estaba en tratamiento con furosemida, nifedipino, espironolactona y tamoxifeno. Deambulaba con bastón, siendo independiente para todas las actividades de la vida diaria básicas (ABVD) con un índice de Barthel (IB) de 100/100, así como las instrumentales (índice de Lawton 8/8), no presentando deterioro cognitivo (Pfeiffer 1 error) y vivía sola con supervisión por unas sobrinas. Al ingreso, secundario a su disnea, su situación funcional era de dependencia para todas las ABVD (IB 50, con control de esfínteres y come sola, para el resto era dependiente).

En la exploración al ingreso destacaba: buena orientación e hidratación; aumento de la presión venosa yugular hasta el ángulo mandibular no colapsándose con la inspiración; leves crepitantes en ambas bases pulmonares, sobre todo en el lado derecho; disminución

Trabajo aceptado: 30 de octubre de 2006

Correspondencia: Javier Gómez Pavón. Servicio de Geriatría.. Hospital Central de la Cruz Roja. Avda. Reina Victoria, 24-26. 28003 Madrid. email: javiergomezpavon@ya.com - osmachosant@yahoo.com 
de los tonos cardiacos; retracción de la mama izquierda con ausencia del pezón; edemas en ambos miembros inferiores hasta rodillas, resto de la exploración anodina, con una saturación de oxígeno 93\%.

En la analítica presentaba hemograma y coagulación normal, con datos de insuficiencia renal crónica (urea $79 \mathrm{mg} / \mathrm{dl}$, creatinina 1,9 $\mathrm{mg} / \mathrm{dl}$ ) con desnutrición (proteínas 5,03 g/dl), el resto de la bioquímica (incluyendo hormonas tiroideas, D-dímero, CEA y AFP) era normal. Radiografía de tórax: cardiomegalia, elevación del hemidiafragma derecho y atelectasia en base derecha. Electrocardiograma con ritmo sinusal con desviación del eje derecho.

$\mathrm{Al}$ ingreso se realizó por alta sospecha clínica una gammagrafía de ventilación-perfusión que resultó con baja probabilidad para tromboembolismo pulmonar. A su vez se realizó un ecocardiograma ante los datos de sobrecarga derecha súbita, que determinó una fracción de eyección del 69\%, con presencia de una masa extracardiaca que colapsaba la aurícula derecha, tras lo cual se realizó un TC toraco-abdominal que detecta la presencia de un quiste hepático gigante que eleva y comprime la aurícula, con dos imágenes sugerentes de LOEs con alta probabilidad de metástasis del carcinoma mamario (Figs. 1 y 2).

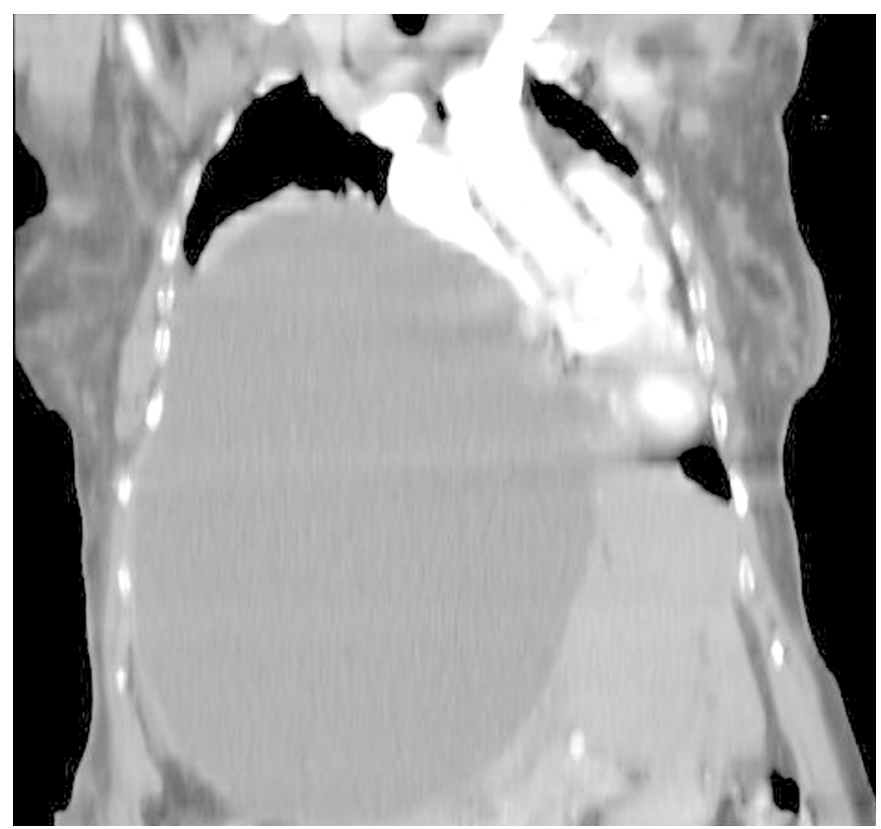

Figura 1. Quiste hepático gigante en región toraco-abdominal, comprimiendo la aurícula derecha.

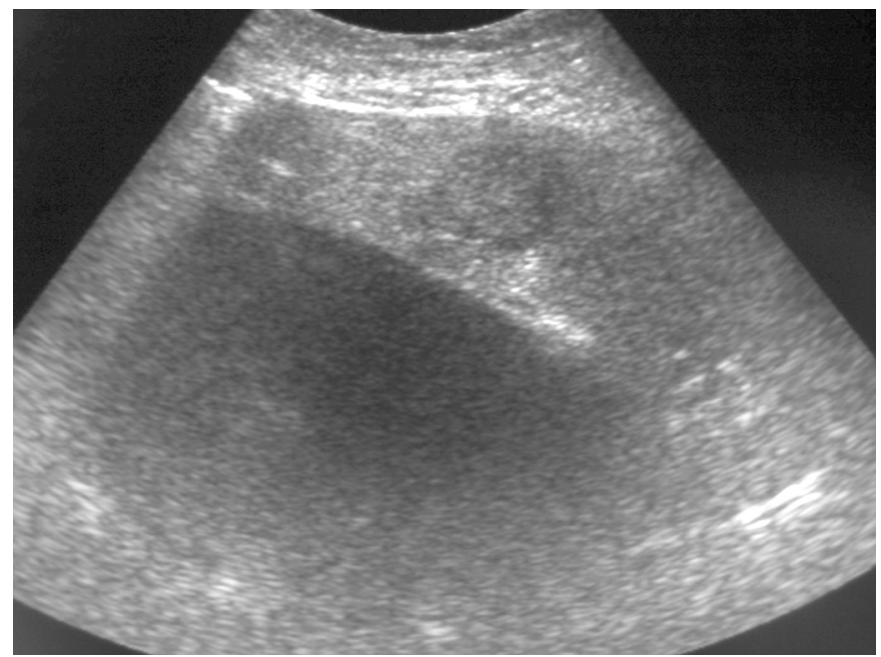

Figu. 2. Quiste hepático gigante y LOE.
Se decidió tratar el quiste gigante mediante actitud curativa con el objetivo de mejorar la sintomatología de la disnea, y recuperar asî el nivel funcional previo de las ABVD. Como tratamiento se realizó el drenaje, dirigido por ecografía, del máximo volumen posible, con la posterior introducción de alcohol al 99\%, para evitar en lo posible la posterior reaparición del quiste. Se extrajo cerca de cuatro litros de líquido, no pudiéndose más ante la tabicación del quiste. Presentó como única complicación durante la intervención dolor que precisó tratamiento agudo con metamizol y tramadol según titulación endovenosos.

Se realizó al alta una ecografía abdominal y un ecocardiograma de control, donde se observa la persistencia del quiste con menor volumen y la compresión en menor medida sobre la aurícula derecha; con clara mejoría sintomática para su disnea (II NYHA). Fue dada de alta a domicilio con ayuda comunitaria y seguimiento del Equipo de Soporte de Ayuda Domiciliaria (ESAD). Se hizo control con TC abdominal a los 3 meses con persistencia del tamaño del quiste y de la disnea grado II, precisando mínima supervisión en el baño con independencia para el resto de ABVD.

\section{DISCUSIÓN}

El diagnóstico diferencial que se plantea ante el hallazgo de una lesión quística hepática se resume en la tabla I (3):

-Absceso piógeno hepático: resultado de una infección bacteriana del parénquima, siendo secundario a gramnegativos (E. coli) y anaerobios de forma polimicrobiana (en caso de diseminación portobiliar). En el caso de la diseminación hematógena suelen ser monomicrobianos por $S$. aureus, estreptococos y gramnegativos aerobios. Se presentan fundamentalmente en ancianos con una sintomatología de febrícula insidiosa, afectación del estado general y dolor en hipocondrio derecho.

-Quiste hidatídico: causada por Equinococcus granulosus. En ecografía presentan una pared más gruesa con tabicaciones y vesículas hijas, detritus hiperecogénicos, así como ocasionalmente calcificaciones en su pared, siendo la serología diagnóstica en hasta el $70 \%$. Se recomienda el tratamiento primario con mebendazol o albendazol o como adyuvante a la resección hepática.

-Cistoadenoma: tumor de origen biliar, con potencial degeneración a cistoadeno-carcinoma. Afecta principalmente a las mujeres, soliendo ser multiloculado.

—Enfermedad poliquística del adulto: enfermedad autosómica dominante, con múltiples quistes renales. Está asociado en un $25 \%$ a quistes hepáticos, que se forman por un desarrollo defectuoso de los conductos biliares intrahepáticos, no

\section{TABLA I}

DIAGNÓSTICO DIFERENCIAL DEL QUISTE HEPÁTICO

\section{- Absceso piógeno hepático}

- Quiste hidatídico

- Cistoadenoma

- Enfermedad quística no parasitaria

o Enfermedad poliquística del adulto

o Fibrosis hepática congénita

o Microhamartoma biliar

o Quiste hepático simple 
estando comunicados con el árbol biliar. La afectación hepática suele ser asintomática.

-Fibrosis hepática congénita: enfermedad autosómica recesiva, con aumento del tamaño de los espacios porta y fibrosis sin nódulos de regeneración. Presenta síntomas de hipertensión portal a edades tempranas (menores de 20 años).

-Complejos de Meyenburg o microhamartoma biliar: son formaciones asintomáticas de conductos biliares dilatados irregulares, que pueden contener bilis, en los espacios portales o periportales.

-Quiste hepático simple: los más frecuentes, hasta un 7\% en adultos. La mitad se presentan como un quiste único asintomático, pudiendo tener desde milímetros a 20 centímetros. Microscópicamente están revestidos de una capa única de células epiteliales y contienen un líquido con agua y sales minerales, pero sin ácidos biliares ni bilirrubina.

En el tratamiento del quiste hepático simple gigante, generalmente mayor de $20 \mathrm{~cm}$ (4), la conducta debe ser expectante cuando los pacientes están asintomáticos, pudiéndose intervenir tras la valoración del tamaño y la localización del quiste, ya sea mediante cirugía de forma laparoscópica o mediante resección del quiste, o bien mediante el drenaje del quiste con posterior introducción de distintos productos para evitar la reaparición del mismo. Las técnicas quirúrgicas presentan un muy bajo grado de complicaciones, siendo las más importantes la recurrencia, entre el 0 y el $11 \%(5,6)$, y la hemorragia (7), ésta fundamentalmente en el caso de la intervención laparoscópica. La laparoscopia no está indicada en el caso de quistes de segmentos posteriores (8). El tratamiento mediante drenaje percutáneo guiado por ecografia está indicado como un tratamiento temporal o cuando existe contraindicación para un procedimiento mayor (9), pudiéndose instilar posteriormente distintos productos para disminuir la recidiva en torno al 5\%, ya sea mediante la introducción de alcohol fenol al 99\% (10) o tetraciclinas (11).

En nuestro caso, la clínica del quiste hepático fue debido a su gran tamaño que comprimía la aurícula derecha dando clínica de insuficiencia cardiaca derecha junto con disnea por la elevación del hemidiafragma derecho y la atelectasia basal derecha.

Aunque se trataba de una paciente con un cáncer de mama en fase terminal, que rechazaba tratamiento activo excepto el continuar con tratamiento paliativo habitual (tamoxifeno), su calidad de vida se vio afectada principalmente por el síntoma disnea de causa potencialmente tratable de forma curativa. A pesar de la enfermedad de base y la elevada edad (93 años), fue su buena situación funcional (independiente para todas las ABVD, IB 100) el elemento base en la toma de decisiones junto con la propia autonomía de la paciente, para mejorar su calidad de vida. Por ello se rechazó el tratamiento quirúrgico y se optó como mejor indicación el drenar el quiste para posteriormente instilar alcohol al $99 \%$.

La adecuada y dinámica toma de decisiones al final de la vida, especialmente en pacientes geriátricos, se debe basar en el pronóstico de la enfermedad, la situación psicofuncional del paciente, la agresividad-beneficio del tratamiento a realizar, el grado de control sintomático, y la opinión del enfermo-familia. La edad de forma aislada aporta información que conduce generalmente a una toma de decisiones erróneas. El control de síntomas en una paciente oncológica terminal independientemente de la edad, no debe de basarse exclusivamente en la paliación, que en este caso hubiera estado constituida por morfina. Si la causa que produce el síntoma se beneficia de un tratamiento curativo activo (en nuestro caso evacuación del quiste), no se debe negar dicho tratamiento, siempre y cuando la situación psicofuncional y la enfermedad así lo permitan (12).

\section{Bibliografía}

1. Pons F, Llovet JM. Actitud a seguir ante una lesión hepática focal. Rev Esp Enferm Dig 2004; 96: 567-77.

2. Caremani M, Vincenti A, Benci A, Sassoli S, Tacconi D. Ecographic epidemiology of non-parasitic hepatic cysts. J Clin Ultrasound 1993; 21: $115-8$.

3. Sala M, Llovet JM, Bruix J. Enfermedades quísticas no parasitarias del hígado y absceso piógeno hepático. En: Rodés J, Guardia J, editores. Medicina Interna $2^{\mathrm{a}}$ edición. Barcelona: Masson; 2004. p. 1530-31.

4. Morino M, de Giuli M, Festa V, Garrone C. Laparoscopic management of symptomatic nonparasitic cysts of the liver. Indications and results. Ann Surg 1994; 219: 157-64.

5. Katkhouda N, Hurwitz M, Gugenheim J, Mavor E, Mason RJ, et al. Laparoscopic management of benign solid and cystic lesions of the liver. Ann Surg. 1999; 229: 460-6.

6. Fiamingo P, Tedeschi U, Veroux M, Cillo U, Brolese A, Da Rold A, et al. Laparoscopic treatment of simple hepatic cysts and polycystic liver disease. Surg Endosc 2003; 17: 623-6.
7. Klingler PJ, Bodner E, Schwelberger HG. Late complication after laparoscopic fenestration of a liver cyst. Surg Laparosc Endosc 1998; 8: 76-7.

8. Ramírez D, Zaldivar FR, Beltrán TA, López S, López JM, Rodríguez A, Vargas A. Quiste hepático gigante. Informe de un caso. Cir Gen 2001; 23: 182-4.

9. Kairaluoma MI, Leinonen A, Stahlberg M, Paivansalo M, Kiviniemi $\mathrm{H}$, Siniluoto T. Percutaneous aspiration and alcohol sclerotherapy for symptomatic hepatic cysts. An alternative to surgical intervention. Ann Surg 1989; 210: 208-15.

10. Andersson R, Jeppsson B, Lunderquist A, Bengmark S. Alcohol sclerotherapy of non-parasitic cysts of the liver. Br J Surg 1989; 76: 254-5.

11. Hagiwara H, Kasahara A, Hayashi N, Kono M, Suzuki K, Kashio S, et al. Successful treatment of a hepatic cyst by one-shot instillation of minocycline chloride. Gastroenterology 1992; 103: 675-7.

12. Morrison RS, Meier DE. Palliative Care. N Engl J Med 2004; 350: 2582-90. 